American Journal of Environmental Sciences 5 (4): 547-555, 2009

ISSN 1553-345X

(C) 2009 Science Publications

\title{
Sorption of Phenols: Influence of Groundwater pH and of Soil Organic Carbon Content
}

\author{
Silvia Fiore and Maria Chiara Zanetti \\ DITAG-Department of Land Environment and Geo-Engineering, Politecnico di Torino, \\ Corso Duca Degli Abruzzi 24, 10129 Torino, Italy
}

\begin{abstract}
Problem statement: Physical and chemical properties of soil, groundwater and pollutants deeply influenced the type and the strength of sorption phenomena involving hydrophobic organic contaminants: Soil fraction of organic carbon (foc) and cation exchange capacity, groundwater $\mathrm{pH}$ and pollutants hydrophobicity were with undoubtedly the predominant issues. Approach: In this study an experimental study of the sorption of phenol and 2-nitrophenol on three soils was performed considering three initial $\mathrm{pH}$ values, with the aim to evaluate the soil/pollutant interactions as a function of the relative abundance of the neutral contaminants and phenolate species and of the solid phase properties. Results: The considered soil samples (a silty clay, a silt and a sand coming from northern Italy) underwent to a physical and chemical characterization: Particle-size, mineralogical and chemical analyses were performed. The experimental data coming from some batch tests, carried employing aqueous phases containing different concentrations of phenol and 2-nitrophenol at initial $\mathrm{pH}$ values equal to 4, 7 and 10, were fitted by means of several isotherm models. Three Dual Mode Models (DMM), employing different isotherm models to represent the sorption of the neutral and the anionic species of the pollutants, were evaluated by the researchers to simulate the sorption of phenol and 2nitrophenol in the examined conditions. Conclusion: The soil/contaminant interaction mechanisms determining the isotherm shapes were discussed: foc appeared to be the main issue, although the nitrogroup was able to promote sorption. In all considered soil samples and at all initial $\mathrm{pH}$ values, the highest foc (found in the silty soil) and the presence of the nitro-group determined the highest amounts of pollutant transferred on the solid phase. The two DMMs proposed by the researchers, implying nonlinearity, showed a higher reliability in simulating experimental data compared to a DMM based on linear sorption isotherms. Main sorption mechanisms were controlled by the partitioning of neutral pollutants in soil organic matter, but also the interactions between the pollutants, both in phenolate and in neutral forms and the soil mineral surface played a primary role.
\end{abstract}

Key words: Phenol, phenolate, nitro-group, sorption, dual mode model

\section{INTRODUCTION}

The factors supervising sorption of Hydrophobic Organic Contaminants (HOCs) depend on the physical and chemical properties of the soil, of the pollutants and of the groundwater. Water solubility, hydrophobicity and identity of the functional groups on the molecule are the pollutant most important properties; temperature, $\mathrm{pH}$, ionic strength and presence of dissolved organic substances may be cited among the groundwater physico-chemical properties. Specific surface, abundance and type of clay minerals and metal oxides, cation exchange capacity, acidity, redox potential and organic carbon content determine the sorptive attitude of a soil.
The Soil Organic Matter (SOM) content is the predominant issue: Considering the sorption of $\mathrm{HOC}_{\mathrm{S}}$ on soils characterized by an appreciable amount of organic carbon (foc $>0.001$ ), absorption is commonly assumed to be the main interaction mechanism. Both linear and nonlinear isotherms have been reported to describe the absorption of HOCs: The homogeneous ideal structure of the SOM is a concept now exceeded and the heterogeneity of the SOM has been demonstrated ${ }^{[1,2]}$.

Adsorption, implying nonlinear isotherms, become relevant in the evaluation of sorption processes concerning soils having a low organic carbon content. Among adsorption active sites, the most abundant are the silanolic groups (in neutral, protonated or

Corresponding Author: Silvia Fiore, DITAG-Department of Land Environment and Geo-Engineering, Politecnico di Torino, Corso Duca Degli Abruzzi 24, 10129 Torino, Italy Tel: +39/011/5647613 Fax: +39/011/5647699 
deprotonated form, depending on groundwater $\mathrm{pH}$ ), able to promote specific interactions (H-bonds respectively with water molecules, anions and cations). Metal oxides (mainly aluminum, iron and manganese oxides and hydroxides), depending on groundwater $\mathrm{pH}$ value, are able to support nonspecific interactions, eventually followed by stronger interactions, such as chemisorption (formation of strong covalent bonds between protonated metal oxides and anionic contaminants) and redox reactions at the soil/aqueous phase interface (between the neutral metal oxides and the neutral form of the pollutants $)^{[3,4]}$.

Phenols are weakly polar Hydrophobic Ionizable Organic Contaminants (HIOCs) widespread in groundwater, because of the massive use of these compounds in industrial processes and agriculture. $\mathrm{HIOC}_{\mathrm{S}}$ toxicity is deeply influenced by groundwater $\mathrm{pH}$ : Ionic species are more soluble in aqueous phase and thus more mobile in the subsoil, although neutral species are more toxic, because they have a high affinity with SOM.

Nonlinear isotherms have been reported in the study of HIOCs' behavior: Sorption processes concern both neutral and ionic species and some interaction mechanisms, involving hydrophobic sorption of neutral and ionic species, forming of ion pairs and ionexchange reactions, have been proposed ${ }^{[5]}$. Several studies $^{[6-8]}$ underline the HIOCs partitioning coefficient $\left(\mathrm{K}_{\mathrm{D}}\right)$ dependence from the aqueous phase $\mathrm{pH}$.

In this study the sorptive potential of three Italian soils was evaluated by means of a physical and chemical characterization and phenol and 2-nitrophenol were taken into account as contaminants. Batch tests were performed on each soil at $\mathrm{pH}$ values equal to 4,7 and 10 and considering pollutants concentration values between 0.5 and $10 \mathrm{mg} \mathrm{L}^{-1}$. The experimental data were fitted by means of linear, Freundlich and Langmuir isotherm models and the soil/contaminant interaction mechanisms were discussed. A comparison between the theoretical values (calculated by means of two Linear Free Energy Relationships (LFERs) already applied to the study of the sorption of phenols) ${ }^{[9,10]}$ and the experimental values of the partitioning coefficient $K_{D}$ was performed and some predictive Dual Mode Models (DMMs), one proposed by other researchers ${ }^{[11]}$ and two proposed by the researchers were applied to the experimental data.

The goal of this study was to underline the phenolate contribution to sorption phenomena considering different natural sorbents and to evaluate the applicability of quantitative relationships (such as LFERs and DMMs) that respectively neglect or consider the phenolate sorption.
Theoretical background: Mathematical predictive models are useful tools for the evaluation of organic pollutants/soil/groundwater interactions on a real scale: They are general laws employing one or more parameters whose values are experimentally determined. In most cases predictive models lead to the calculation of the $K_{D}$ value, in order to foresee the amount of the pollutant transferred in soil organic fraction. Predictive models are usually based on the properties of the soil (mainly foc), of the pollutant (hydrophobicity, polarity, water solubility, structural characteristics) and of the aqueous phase $(\mathrm{pH}$, ionic strength, redox potential).

Monoparametric LFERs are equations based on a parameter which value is determined by a specific property of the pollutant (usually the hydrophobicity, by means of the octanol/water partitioning model and its coefficient $\mathrm{K}_{\mathrm{OW}}$ ) and two coefficients, obtained from the experimental data regression. In this study the experimental data obtained by means of the batch tests are compared with the partitioning coefficients values calculated employing two LFERs, already applied in literature to the study of the sorption of phenols. The first relation (Eq. 1) ${ }^{[10]}$ is based on the octanol/water partitioning model and the second (Eq. 2) ${ }^{[9]}$ on the neutral pollutant (HA) water solubility (Eq. 3). Both considered LFERs assume that the main sorption mechanism is the partitioning of the neutral pollutant (HA) in soil organic fraction and the $\mathrm{K}_{\mathrm{D}}$ dependence from $\mathrm{pH}$ (Eq. 4):

$\log \mathrm{K}_{\mathrm{OC}}=0.97\left(\log \mathrm{K}_{\mathrm{OW}}\right)-0.094$

$\log \mathrm{K}_{\mathrm{OC}}=-0.686 \log \mathrm{S}(\mathrm{pH})+4.273$

$\mathrm{S}(\mathrm{pH})=\mathrm{S}_{\mathrm{HA}}\left(1+10^{\mathrm{pH}-\mathrm{pKa}}\right)$

$\mathrm{K}_{\mathrm{D}}(\mathrm{HA})=\alpha$ foc $\mathrm{K}_{\mathrm{OC}}$

Where:

$\mathrm{K}_{\mathrm{D}}(\mathrm{HA})=$ Neutral pollutant partitioning coefficient

$\alpha=$ Amount of neutral pollutant

foc $\quad=$ Soil organic carbon fraction

$\mathrm{K}_{\mathrm{OC}}=$ Neutral pollutant partitioning coefficient referred to the organic carbon content of the soil

$\mathrm{K}_{\mathrm{OW}}=$ Neutral pollutant octanol/water partitioning coefficient

$\mathrm{S}_{\mathrm{HA}} \quad=$ Water solubility of the pollutant

$\mathrm{S}(\mathrm{pH}) \quad=$ Water solubility of the pollutant at a certain $\mathrm{pH}$ value

DMMs rise from the study of polymeric materials and from the hypothesis of the presence in SOM of 
hard/glassy and soft/rubbery domains, both porous regions whose structure is deformed by the pollutants ${ }^{[14]}$. Absorption involves a three-dimensional organic matrix, made of regions having different properties and not equally accessible for the pollutants, thus determining the coexistence of domains that produce linear isotherms (deriving from non specific interactions, such as Van der Waals forces, between the pollutants and soft organic carbon) and of domains that produce non linear isotherms (deriving from specific interactions, such as H-bonds, between pollutants and hard organic carbon). A simple DMM represents the dissolution of the pollutant though hydrophobic attraction in the rubbery domain by means of a linear term and the penetration in the cavities of the glassy domain by means of a Langmuir term ${ }^{[15]}$. Therefore a linear behavior is hypothesized for the interactions with soft organic carbon and nonlinearity (due to the heterogeneity and availability of active sites and competition phenomena) is hypothesized for the interactions with hard organic carbon.

\section{MATERIALS AND METHODS}

Soil characterization: The particle-size analysis was performed by means of dry mechanical sieving, of manual wet sieving and of Andreasen apparatus depending on the considered dimensional range. The mineral components were analyzed by means of a Xray Rigaku D/max spectrometer $(40 \mathrm{kV}, 30 \mathrm{~mA}$, scan speed 10-0.01). The Cation Exchange Capacity (CEC), organic carbon fraction (foc) and the carbonate content values were obtained by means of reference procedures $^{[12]}$.

Batch tests: Ten gram of dried and sterilized (Autoclave ASAL 760, $1 \mathrm{~h}$ at $120 \mathrm{kPa}$ ) soil were put in $150 \mathrm{~mL}$ Erlenmeier flasks with $40 \mathrm{~mL}$ of phenol and 2nitrophenol solutions of different concentrations (0.5-12-5-10 ppm), 0.2\% $\mathrm{NaN}_{3}, \mathrm{I}=0.015 \mathrm{M}$ employing $\mathrm{CaCl}_{2}$ as background electrolyte, capped with Parafilm and covered with aluminum foil. The $\mathrm{pH}$ was adjusted at values equal to 4, 7 and 10 using 1-5 drops of $0.1 \mathrm{~N}$ $\mathrm{HCl}$ or $\mathrm{NaOH}$. The batch tests were performed shaking the flasks (ASAL 711 orbital shaker, $250 \mathrm{rpm}, 72 \mathrm{~h}$, $20^{\circ} \mathrm{C}$ ). Kinetic experiments showed that equilibrium was essentially reached after $72 \mathrm{~h}$ and the competition in sorption processes for phenol and 2-nitrophenol was verified to be absent. Four replicates and two blanks were set for each pollutants concentration at the three $\mathrm{pH}$ values. The batch tests solutions were then centrifugated (ALC PK 110 centrifuge, $3000 \mathrm{rpm}, 30 \mathrm{~min}$ ) in $100 \mathrm{~mL}$ glass tubes and weighted. After $72 \mathrm{~h}$ all the aqueous phases exhibited $\mathrm{pH}$ values between 7.66 and 8.05.

Solid-phase extraction: The supernatant aqueous phases were extracted (Supelco Visiprep Vacuum Manifold, Supelco ENVI-Chrom tubes $0.5 \mathrm{~g}, 6 \mathrm{~mL}$ ) in Methyl Ter Butyl Ether (MTBE) and weighted. The calibration standards underwent the same procedure.

GC-FID Analysis: As $4 \mu \mathrm{L}$ of each sample was injected in a HP 6890 GC equipped with a FID and a HP-5 capillary column. The calibration and GC parameters are reported in a previous study of the researchers $^{[13]}$.

Reagents: Stock standard solutions (2000 ppm) were prepared from phenol (Aldrich, >99\%) and 2nitrophenol (Merck, >99\%). All the solutions employed in the GC calibration and in the batch tests were prepared by weighting.

\section{RESULTS}

Some physical and chemical properties of the considered pollutants are schematized in Table 1. The results of the soil samples characterization are reported in Table 2.

The experimental data gathered by means of the batch tests performed at initial $\mathrm{pH}$ values equal to 4,7 and 10 were submitted to regression using the linear (Eq. 5), Freundlich (Eq. 6) and Langmuir (Eq. 7) isotherm models (by means of Data Fit 8.0 software, Oakdale Engineering), fitting 20 experimental points for each sorption isotherm:

$$
\begin{aligned}
& \mathrm{Cs}_{\mathrm{s}}=\mathrm{K}_{\mathrm{D}} \mathrm{C}_{\mathrm{AQ}} \\
& \mathrm{Cs}_{\mathrm{S}}=\mathrm{K}_{\mathrm{F} \cdot \mathrm{C}_{\mathrm{AQ}}{ }^{\mathrm{n}}} \\
& \mathrm{C}_{\mathrm{S}}=\frac{\mathrm{K}_{\mathrm{L}} \mathrm{C}_{\mathrm{AQ}} \mathrm{C}_{\mathrm{S} \text {, max }}}{1+\mathrm{K}_{\mathrm{L}} \mathrm{C}_{\mathrm{AQ}}}
\end{aligned}
$$

Where:

$\mathrm{C}_{\mathrm{S}}=$ Equilibrium contaminant concentration in the soil $\left(\mathrm{mg} \mathrm{kg}^{-1}\right)$

$\mathrm{C}_{\mathrm{AQ}}=$ Equilibrium contaminant concentration in the liquid phase $\left(\mathrm{mg} \mathrm{L}^{-1}\right)$

$\mathrm{C}_{\mathrm{S}, \max }=$ Maximum contaminant concentration in the soil $\left(\mathrm{mg} \mathrm{kg}^{-1}\right)$

$\mathrm{K}_{\mathrm{F}} \quad=$ Freundlich constant

$\mathrm{n}=$ Surfacial active sites energy distribution index

$\mathrm{K}_{\mathrm{L}} \quad=$ Langmuir constant 
Am. J. Environ. Sci., 5 (4): 547-555, 2009

Table 1: Some properties of phenol and 2-nitrophenol ${ }^{[16]}$

\begin{tabular}{|c|c|c|c|c|c|c|}
\hline & \multirow{2}{*}{$\begin{array}{l}\text { Aqueous } \\
\text { solubility }(20 \\
\left.-25^{\circ} \mathrm{C}, \mathrm{mol} \mathrm{L}^{-1}\right)\end{array}$} & \multirow{2}{*}{$\begin{array}{l}\log \mathrm{K}_{\mathrm{OW}} \\
\left(20-25^{\circ} \mathrm{C}\right)\end{array}$} & \multirow{2}{*}{$\begin{array}{l}\mathrm{pKa} \\
\left(25^{\circ} \mathrm{C}\right)\end{array}$} & \multicolumn{3}{|c|}{$\alpha_{0}\left(25^{\circ} \mathrm{C}\right)$} \\
\hline & & & & pH 4 & $\mathrm{p}$ & pH 10 \\
\hline & 0.890 & 1.45 & 9.82 & 0.9999 & 85 & 0.3 \\
\hline & 0.008 & 1.89 & 7.17 & 0.9993 & 0.5966 & 0.00 \\
\hline
\end{tabular}

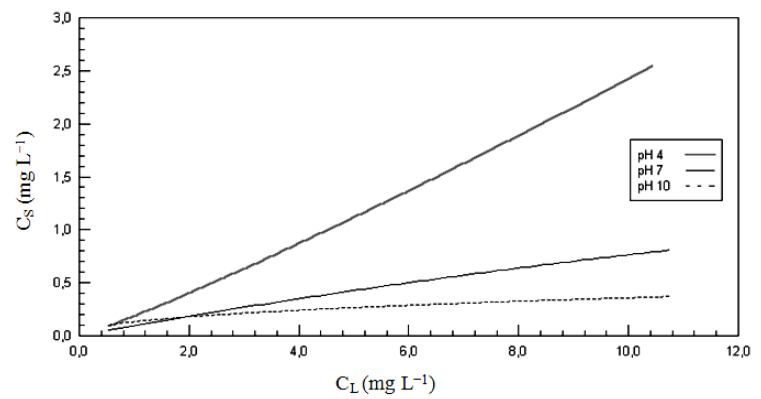

(a)

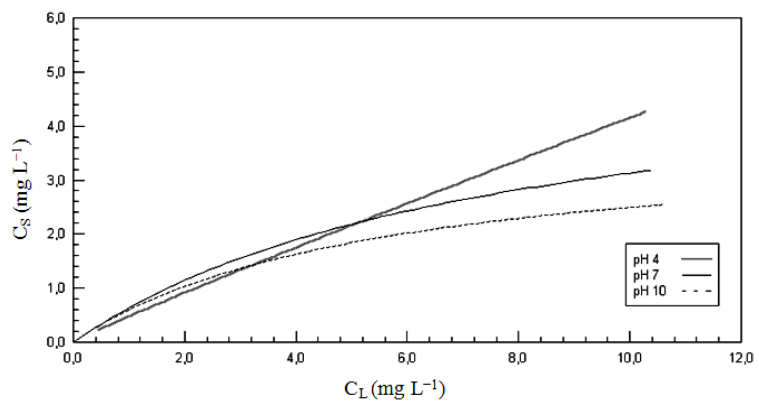

(b)

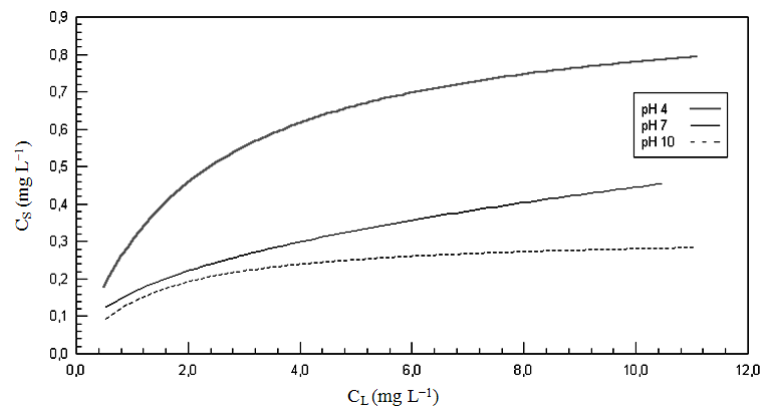

(c)

Fig. 1: Sorption isotherms of phenol on Crescentino (a), Asti 1 (b) and Asti 2 (c) soil samples at pH values equal to 4,7 and 10

The results of the regression of the experimental data obtained from the batch tests are shown in Table 3 and the isotherms obtained from the best fitting models (Table 3) are represented in Fig. 1 and 2.

The calculation of the partitioning coefficients by means of Eq. 1-4 allowed the researchers to obtain the

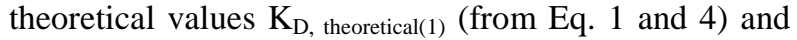
$\mathrm{K}_{\mathrm{D} \text {, theoretical(2) }}$ (from Eq. 2-4) referred to phenol at $\mathrm{pH}$ values equal to 4 and 7 and to 2-nitrophenol at $\mathrm{pH} 4$.
Table 2: Soil samples characterization

\begin{tabular}{|c|c|c|c|}
\hline & Crescentino & Asti 1 & Asti 2 \\
\hline $\begin{array}{l}\text { Mineral } \\
\text { components }\end{array}$ & $\begin{array}{l}\text { Quartz, feldspar, } \\
\text { illite, chlorite, } \\
\text { smectite }\end{array}$ & $\begin{array}{l}\text { Quartz, feldspar, } \\
\text { illite, chlorite, } \\
\text { kaolinite, calcite }\end{array}$ & $\begin{array}{l}\text { Quartz, feldspar, } \\
\text { illite, chlorite, } \\
\text { kaolinite, calcite }\end{array}$ \\
\hline Particle-size & $33 \%$ clay, $50 \%$ & $10 \%$ clay, $83 \%$ & $\begin{array}{l}8 \% \text { silt, } \\
82 \% \text { sand }\end{array}$ \\
\hline $\mathrm{d}_{50}(\mathrm{~mm})$ & 0.0100 & 0.1000 & 0.2000 \\
\hline $\begin{array}{l}\text { CEC } \\
(\mathrm{meq} / 100 \mathrm{~g})\end{array}$ & 6.2300 & 5.1200 & 3.0300 \\
\hline $\mathrm{CaCO}_{3}(\%)$ & 1.0900 & 11.8700 & 11.580 \\
\hline foc & 0.0034 & 0.0099 & 0.0007 \\
\hline $\mathrm{Fe}(\%)$ & 4.1000 & 3.8700 & 1.3900 \\
\hline $\mathrm{Al}(\%)$ & 3.6300 & 6.7800 & 2.1200 \\
\hline $\mathrm{M}$ & 0.1000 & 0.0500 & 0.0300 \\
\hline
\end{tabular}

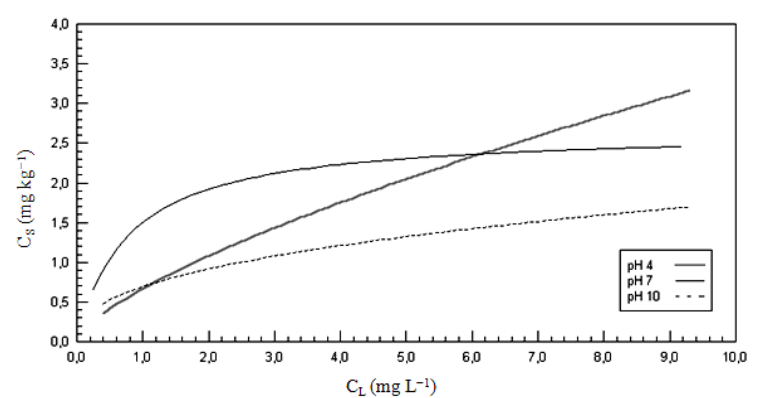

(a)

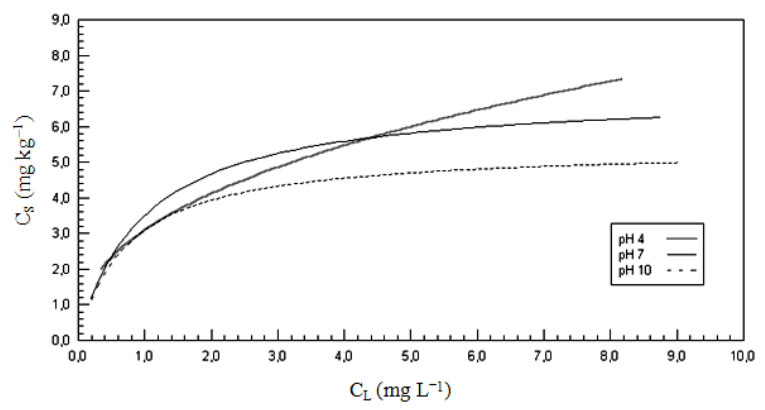

(b)

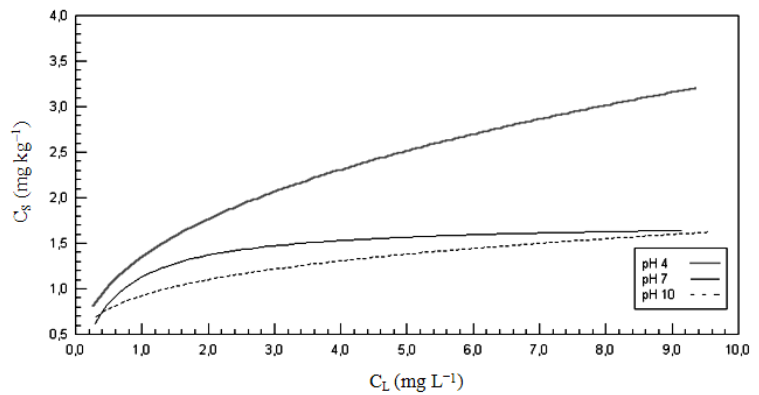

(c)

Fig. 2: Sorption isotherms of 2-nitrophenol on Crescentino. (a): Asti 1; (b): Asti 2; (c): Soil at $\mathrm{pH}$ values equal to 4,7 and 10

The partitioning coefficient theoretical values are compared with the experimental values $\left(\mathrm{K}_{\mathrm{D} \text {, experimental }}\right)$ obtained from linear models in Table 4. 
Am. J. Environ. Sci., 5 (4): 547-555, 2009

Table 3: Regression of the experimental data concerning phenol and 2-nitrophenol sorption

\begin{tabular}{|c|c|c|c|c|c|c|c|c|c|}
\hline & \multicolumn{3}{|c|}{ Linear model } & \multicolumn{3}{|c|}{ Freundlich model } & \multicolumn{3}{|c|}{ Langmuir model } \\
\hline & pHi* & $K_{D}$ & $\mathrm{R}^{2}$ & $\mathrm{~K}_{\mathrm{F}}$ & $\mathrm{n}$ & $\mathrm{R}^{2}$ & $\mathrm{~K}_{\mathrm{L}}$ & $\mathrm{C}_{\mathrm{S}, \max }$ & $\mathrm{R}^{2}$ \\
\hline \multicolumn{10}{|c|}{$\begin{array}{l}\text { Crescentino soil } \\
(\mathrm{pHf} * *=7.78 \pm 0.2)\end{array}$} \\
\hline \multirow[t]{4}{*}{ Phenol } & 4 & 0.2459 & 0.9838 & 0.2123 & 1.0581 & 0.9853 & 0.0029 & 92.1377 & 0.9828 \\
\hline & 7 & 0.0745 & 0.9541 & 0.1083 & 0.8509 & 0.9591 & 0.0341 & 3.0014 & 0.9612 \\
\hline & 10 & 0.0217 & 0.8203 & 0.1321 & 0.3910 & 0.9352 & 0.4917 & 0.3714 & 0.9518 \\
\hline & 4 & 0.3420 & 0.9704 & 0.6842 & 0.7230 & 0.9713 & 0.0788 & 8.0342 & 0.9604 \\
\hline \multirow[t]{2}{*}{ 2-nitrophenol } & 7 & 0.1885 & 0.6838 & 1.1875 & 0.3521 & 0.8165 & 0.8604 & 2.7601 & 0.8789 \\
\hline & 10 & 0.1279 & 0.7938 & 0.8821 & 0.3388 & 0.9240 & 0.8143 & 2.0220 & 0.9603 \\
\hline \multicolumn{10}{|c|}{$\begin{array}{l}\text { Asti } 1 \text { soil } \\
(\mathrm{pHf} * *=7.70 \pm 0.05)\end{array}$} \\
\hline \multirow[t]{4}{*}{ Phenol } & 4 & 0.4291 & 0.9345 & 0.5386 & 0.9153 & 0.9318 & 0.0119 & 41.8468 & 0.9296 \\
\hline & 7 & 0.2872 & 0.9430 & 0.6286 & 0.7015 & 0.9716 & 0.1186 & 5.8193 & 0.9858 \\
\hline & 10 & 0.1954 & 0.8770 & 0.6812 & 0.5470 & 0.9210 & 0.2135 & 3.5011 & 0.9391 \\
\hline & 4 & 0.8602 & 0.9645 & 1.4717 & 0.7853 & 0.9556 & 0.0367 & 33.5682 & 0.9466 \\
\hline \multirow{2}{*}{ 2-nitrophenol } & 7 & 0.3440 & 0.5313 & 3.3550 & 0.2502 & 0.6835 & 1.7738 & 6.1043 & 0.8959 \\
\hline & 10 & 0.4463 & 0.7267 & 2.7108 & 0.3425 & 0.8570 & 1.1332 & 5.9257 & 0.9169 \\
\hline \multicolumn{10}{|c|}{$\begin{array}{l}\text { Asti } 2 \text { soil } \\
(\mathrm{pHf} * *=7.94 \pm 0.08)\end{array}$} \\
\hline \multirow[t]{4}{*}{ Phenol } & 4 & - & - & 0.3219 & 0.3896 & 0.8022 & 0.4679 & 0.9468 & 0.9579 \\
\hline & 7 & - & - & 0.1640 & 0.4341 & 0.8964 & 0.3922 & 0.5399 & 0.8746 \\
\hline & 10 & - & - & 0.1405 & 0.3144 & 0.7628 & 0.7669 & 0.3178 & 0.9199 \\
\hline & 4 & - & - & 1.1798 & 0.3751 & 0.9175 & 0.7104 & 2.9341 & 0.8001 \\
\hline \multirow[t]{2}{*}{ 2-nitrophenol } & 7 & - & - & 0.9764 & 1.0650 & 0.5651 & 1.8651 & 1.7358 & 0.9165 \\
\hline & 10 & - & - & 0.9264 & 0.2480 & 0.9366 & 1.7098 & 1.5855 & 0.9771 \\
\hline
\end{tabular}

*: pHi: $\mathrm{pH}$ values measured before the batch tests **: $\mathrm{pHf}$ : $\mathrm{pH}$ values measured at the end of batch tests

Table 4: Experimental and theoretical values of the partitioning coefficients

\begin{tabular}{llll}
\hline & $\mathrm{K}_{\mathrm{D} \text {, experimental }}$ & $\mathrm{K}_{\mathrm{D} \text {, theoretical(1) }}$ & $\mathrm{K}_{\mathrm{D} \text {, theoretical(2) }}$ \\
\hline $\begin{array}{l}\text { Crescentino soil: } \\
\text { phenol, pH 4 }\end{array}$ & 0.2459 & 0.0698 & 0.0253 \\
phenol, pH 7 & 0.0745 & 0.0697 & 0.0253 \\
phenol, pH 10 & 0.0217 & 0.0278 & 0.0134 \\
2-nitrophenol, pH 4 & 0.3420 & 0.1864 & 0.2974 \\
2-nitrophenol, pH 7 & 0.1885 & 0.1113 & 0.2087 \\
$\begin{array}{l}\text { Asti 1 soil: } \\
\text { phenol, pH 4 }\end{array}$ & 0.4291 & 0.2033 & 0.0737 \\
phenol, pH 7 & 0.2872 & 0.2030 & 0.0736 \\
phenol, pH 10 & 0.1954 & 0.0809 & 0.0392 \\
2-nitrophenol, pH 4 & 0.8602 & 0.5432 & 0.8658 \\
2-nitrophenol, pH 7 & 0.3440 & 0.3240 & 0.6078 \\
Asti 2 soil: & & & \\
phenol, pH 4 & 0.0864 & 0.0144 & 0.0052 \\
phenol, pH 7 & 0.0506 & 0.0143 & 0.0052 \\
phenol, pH 10 & 0.0326 & 0.0057 & 0.0028 \\
2-nitrophenol, pH 4 & 0.3455 & 0.0384 & 0.0612 \\
2-nitrophenol, pH 7 & 0.2308 & 0.0229 & 0.0430 \\
\hline
\end{tabular}

\section{DISCUSSION}

Data reported in Table 1 underline the higher hydrophobicity and acidity of 2-nitrophenol in comparison with phenol. The molar fraction $\left(\alpha_{0}\right)$ values show that phenol is mainly in neutral form at $\mathrm{pH}$ values equal to 4 and 7 and extensively dissociated at $\mathrm{pH} 10$; 2-nitrophenol is mainly in neutral form at $\mathrm{pH} 4$, partially dissociated at $\mathrm{pH} 7$ and for the most part in phenolate form at $\mathrm{pH} 10$.
The considered soils are different (Table 2) concerning particle-size distribution, mineral components (clays and other phyllosilicates, such as smectite, illite and kaolinite, have a high tendency to adsorb HOCs), Cation Exchange Capacity, foc and some metal contents. Asti 1 and Asti 2 samples are characterized by a high content of carbonate minerals, that exert a dominating influence on soil buffering properties (see final $\mathrm{pH}$ values measured at the end of batch tests in Table 3).

The isotherm shapes shown in Fig. 1 and 2 suggest the existence of several sorption mechanisms, depending on the pollutant, the soil sample and the $\mathrm{pH}$. The linear model assumes hydrophobic partitioning of the neutral pollutant as the only sorption mechanism, thus a foc $>0.001$ and a $\mathrm{pH}$ value below the pollutant $\mathrm{pKa}$ are requested; for this reason the linear model wasn't applied to the experimental data obtained from Asti 2 sample.

At $\mathrm{pH} 4$ the sorption isotherms have a linear shape considering both pollutants on Crescentino soil and phenol on Asti 1 soil, therefore may be hypothesized that the leading transport mechanism at $\mathrm{pH} 4$ is the partitioning of the neutral species in soil organic matter, but also non specific and specific interactions on the active sites of soil mineral surface may happen, leading to nonlinearity in the case of phenol on Asti 2 soil and of 2-nitrophenol on Asti 1 and Asti 2 soils. In fact for $\mathrm{pH}$ values below the Point of Zero Charge (PZC) the charge of active sites such as metallic oxides becomes positive. 
At pH 7 only phenol sorption isotherms on Crescentino soil have a linear shape, in all other cases nonlinearity occurs. The main sorption mechanism may be again hypothesized the partitioning of the neutral form in soil organic matter. The sorption extent decreases from $\mathrm{pH} 4$ to $\mathrm{pH}$ 7: This is probably caused by the formation of hydrogen bonds between phenol and water molecules, surface active sites and water molecules and phenol and surface active sites.

The calculation of the partitioning coefficients by means of Eq. 1-4 allowed the researchers to obtain the

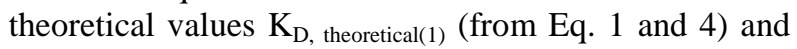

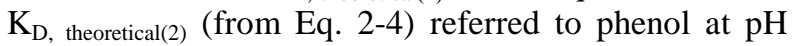
values equal to 4 and 7 and to 2 -nitrophenol at $\mathrm{pH} 4$. The partitioning coefficient theoretical values are compared with the experimental values $\left(\mathrm{K}_{\mathrm{D}}\right.$, experimental $)$ obtained from linear models in Table 4.

These hydrogen bonds make the partitioning of the neutral phenol more difficult at $\mathrm{pH} 7$ than at $\mathrm{pH} 4$. Considering the sorption of 2-nitrophenol at $\mathrm{pH} \mathrm{7,} \mathrm{the}$ partitioning of neutral and phenolate species may be probably accompanied by a low chemisorption and oxidation on the metallic active sites.

At $\mathrm{pH} 10$ in all cases sorption isotherms have nonlinear shapes. In fact the partitioning of the neutral species and the oxidation on surface active sites concern a limited number of molecules and the partitioning of the phenolate is prevented by the repulsion of the surface negative charge of the soil particles. In fact for $\mathrm{pH}$ values above the PZC the charge of active sites becomes negative.

In all soil samples and at all considered $\mathrm{pH}$ values 2-nitrophenol sorption is higher than phenol sorption. Actually the nitro-group stabilizes the phenolate for inductive effect and resonance ${ }^{[16]}$, enhances the pollutant hydrophobicity by means of the creation of intra-molecular $\mathrm{H}$-bonds thus promoting absorption ${ }^{[9]}$. Nitro-aromatics adsorption concerns mainly specific interactions with clay minerals: Electron DonorAcceptor (EDA) complexes are formed in consequence of a coplanar arrangement between oxygen's at the siloxane surfaces of clays (e-donors) and the nitrogroup (e-acceptor) ${ }^{[17]}$.

Quartz, feldspar and other tectosilicates have a lower tendency to form EDA complexes with nitroaromatics because of their $3 \mathrm{~d}$ conformation of siloxane oxygen's, that prevents coplanarity. Iron and aluminum oxides and hydroxides and carbonate minerals promote nonspecific adsorption and iron and manganese adsorbed on hydroxides lead to reductive degradation of the contaminants ${ }^{[18,19]}$. Moreover the higher sorption of 2-nitrophenol at $\mathrm{pH} 10$ on Asti 1 soil, compared to Crescentino and Asti 2 samples, is linked to the organic carbon content of the soil and may be considered a proof of the absorption of the 2-nitrophenolate.

In most cases the theoretical values, especially the ones calculated considering the pollutant solubility $\mathrm{K}_{\mathrm{D}}$, theoretical(2), are lower than the experimental values, particularly taking into account Asti 2 soil because of its low foc. Although a good agreement between experimental and calculated values was obtained considering Crescentino soil (phenol at $\mathrm{pH} 7$ and 10,

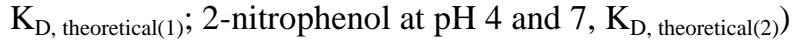

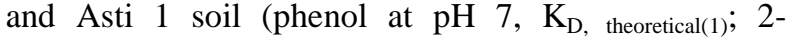
nitrophenol at $\mathrm{pH} 4$ and 7 , respectively $\mathrm{K}_{\mathrm{D} \text {, theoretical(2) }}$ and $\mathrm{K}_{\mathrm{D}}$, theoretical(1)). Considering 2-nitrophenol, the $\mathrm{K}_{\mathrm{D}}$, theoretical(2) values, obtained employing a LFER based on the water solubility, that is much higher for the phenolate, are closer to the experimental data than the

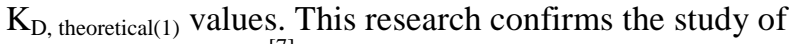
other researchers ${ }^{[7]}$ : they demonstrated that for chlorophenols in aqueous phases having $\mathrm{I} \leq 0.001 \mathrm{M}$ the overall sorption is dominated by the partitioning of the neutral species in $\mathrm{SOM}$ and that if $\mathrm{pH}-\mathrm{pKa} \leq 1$ the contribution of phenolate sorption may be neglected.

The researchers applied some DMMs to the experimental data. In a first DMM (named A model), studied by other researchers ${ }^{[11]}$, the sorption of the neutral form is expressed by means of a linear isotherm (Eq. 8, $\mathrm{K}_{\mathrm{D}}$ value obtained at $\mathrm{pH}<<\mathrm{pKa}$ ) and the behavior of the phenolate is modeled by means of a Langmuir isotherm (Eq. 9, Langmuir parameters obtained at $\mathrm{pH}>>\mathrm{pKa})$. The total concentration of the pollutant $\left(\mathrm{C}_{\mathrm{S} \text {,tot }}\right)$ transferred on the soil is given by the sum of the contributes of the neutral $\left(\mathrm{C}_{\mathrm{S}, \mathrm{HA}}\right)$ and dissociated $\left(\mathrm{C}_{\mathrm{S}, \mathrm{A}^{-}}\right)^{-}$) species:

$$
\begin{aligned}
& \mathrm{C}_{\mathrm{S}, \mathrm{HA}}=\mathrm{K}_{\mathrm{D}} \cdot \mathrm{C}_{\mathrm{L}, \mathrm{HA}} \\
& \mathrm{C}_{\mathrm{S}, \mathrm{A}-}=\frac{\mathrm{C}_{\mathrm{L}, \mathrm{A}-} \cdot \mathrm{K}_{\mathrm{L}} \cdot \mathrm{C}_{\mathrm{S}, \max }}{1+\mathrm{C}_{\mathrm{L}, \mathrm{A}-} \cdot \mathrm{K}_{\mathrm{L}}} \\
& \mathrm{C}_{\mathrm{S}, \text { tot }}=\mathrm{C}_{\mathrm{S}, \mathrm{HA}}+\mathrm{C}_{\mathrm{S}, \mathrm{A}-} \\
& \mathrm{C}_{\mathrm{L}, \mathrm{HA}}=\alpha \cdot \mathrm{C}_{\mathrm{L}} \\
& \mathrm{C}_{\mathrm{L}, \mathrm{A}-}=\mathrm{C}_{\mathrm{L}}-\mathrm{C}_{\mathrm{L}, \mathrm{HA}}
\end{aligned}
$$

Where:

$\mathrm{C}_{\mathrm{S}, \mathrm{HA}}=$ Un-dissociated pollutant concentration transferred on solid phase $\left(\mathrm{mg} \mathrm{kg}^{-1}\right)$

$\mathrm{C}_{\mathrm{S}, \mathrm{A}-}=$ Anionic pollutant concentration transferred on solid phase $\left(\mathrm{mg} \mathrm{kg}^{-1}\right)$

$\mathrm{C}_{\mathrm{S} \text {,tot }}=$ Total pollutant concentration transferred on solid phase $\left(\mathrm{mg} \mathrm{kg}^{-1}\right)$ 
$\mathrm{C}_{\mathrm{L}, \mathrm{HA}}=$ Un-dissociated pollutant concentration in liquid phase $\left(\mathrm{mg} \mathrm{L}^{-1}\right)$

$\mathrm{C}_{\mathrm{L}, \mathrm{A}-}=$ Anionic pollutant concentration in liquid phase $\left(\mathrm{mg} \mathrm{L}^{-1}\right)$

$\mathrm{C}_{\mathrm{L}}=$ Total pollutant concentration in liquid phase $\left(\mathrm{mg} \mathrm{L}^{-1}\right)$

$\mathrm{K}_{\mathrm{D}} \quad=$ Linear isotherm slope at $\mathrm{pH}<\mathrm{pK}_{\mathrm{a}}$

$\mathrm{K}_{\mathrm{L}} \quad=$ Langmuir constant obtained from the isotherm at $\mathrm{pH}>\mathrm{pK}_{\mathrm{a}}$

$\mathrm{C}_{\mathrm{S}, \max }=$ Langmuir constant obtained from the isotherm at $\mathrm{pH}>\mathrm{pK}_{\mathrm{a}}$

The researchers employed in "A" DMM model ${ }^{[11]}$ the following data (Table 4): $\mathrm{K}_{\mathrm{D}}$ at $\mathrm{pH} 7$ and $\mathrm{K}_{\mathrm{L}}$ and $\mathrm{C}_{\mathrm{S}}$, $\max$ at $\mathrm{pH} 10$ for both phenol and 2-nitrophenol.

The researchers propose two other DMMs: A first one, named " $\mathrm{B}$ " model, in which the total sorption is calculated by the sum of the sorption of the neutral pollutant (described by means of a Freundlich isotherm, using the $\mathrm{K}_{\mathrm{F}}$ and $\mathrm{n}$ values obtained at $\mathrm{pH} 10$ for phenol and at $\mathrm{pH} 7$ for 2-nitrophenol) and the sorption of the phenolate (described by means of a Langmuir isotherm, using the $\mathrm{K}_{\mathrm{L}}$ and $\mathrm{C}_{\mathrm{s} \text {, max }}$ values obtained at $\mathrm{pH} 10$ for both pollutants). The equilibrium concentrations of the neutral and anionic forms of the pollutant in the liquid phase are calculated as described for " $\mathrm{A}$ " model.

In the second DMM proposed by the researchers, named "C" model, the total sorption is calculated by the

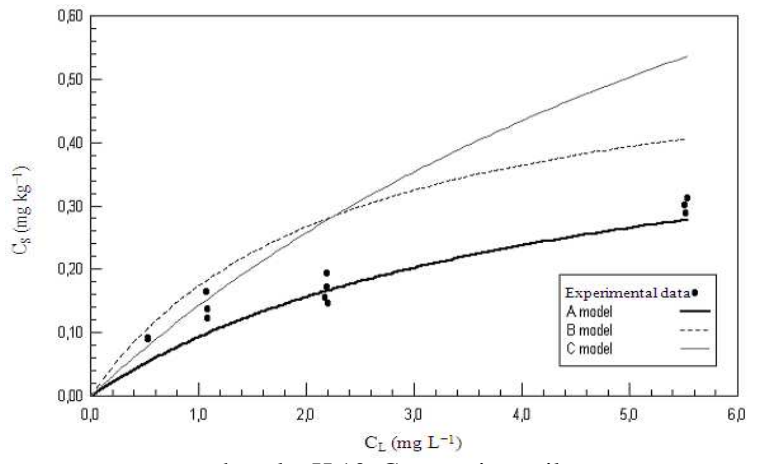

phenol, pH 10, Crescentino soil

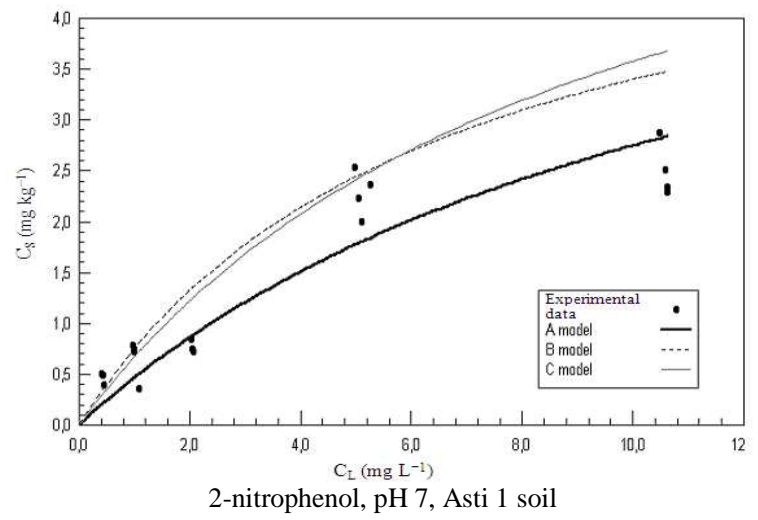

sum of the sorption of the neutral pollutant (described by means of a Langmuir isotherm, using the $\mathrm{K}_{\mathrm{L}}$ and $\mathrm{C}_{\mathrm{s}}$, $\max$ values obtained at $\mathrm{pH} 10$ for phenol and at $\mathrm{pH} 7$ for 2-nitrophenol) and the sorption of the phenolate (described by means of a Langmuir isotherm, using the $\mathrm{K}_{\mathrm{L}}$ and $\mathrm{C}_{\mathrm{s}, \max }$ values obtained at $\mathrm{pH} 10$ for both pollutants). The equilibrium concentrations of the neutral and anionic forms of the pollutant in the liquid phase are calculated as described for " $\mathrm{A}$ " model.

The application of the three DMMs to the sorption of phenol may feel the effects of the lack of data referred to a $\mathrm{pH}$ value at which the pollutant is completely dissociated (i.e., $\mathrm{pH} 12$, at which $\alpha=0.0066$; at $\mathrm{pH} 10$, $\alpha=0.3978$ ), because these data may be used to calculate the anionic pollutant sorption, although a such high $\mathrm{pH}$ value is quite uncommon in groundwater. The application of DMMs to the sorption of 2-nitrophenol at $\mathrm{pH} 7$ happens in the best conditions, because experimental data at $\mathrm{pH} 7$ (to calculate the sorption of the neutral pollutant) and at $\mathrm{pH} 10$ (to calculate the sorption of the phenolate) were available for the researchers.

The three DMMs were applied considering the experimental data obtained at $\mathrm{pH}$ values that guarantee a relevant abundance of both the neutral and anionic fractions of the pollutants $(\mathrm{pH} 10$ for phenol and $\mathrm{pH} 7$ for 2-nitrophenol). The experimental data and the sorption isotherms calculated applying the above described DMMs are shown in Fig. 3.

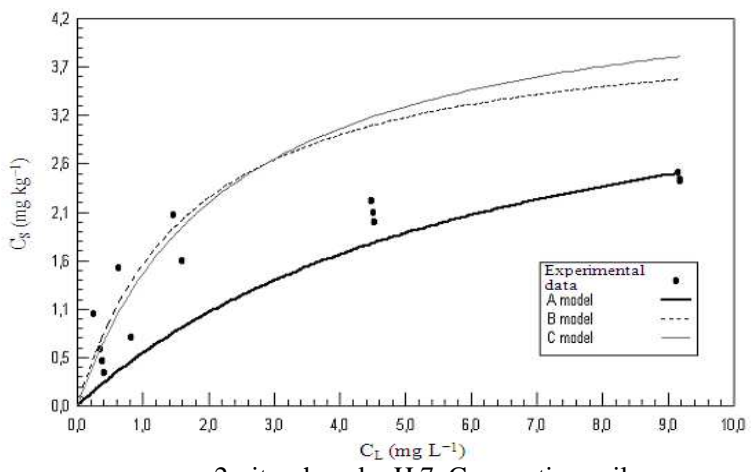

2-nitrophenol, pH 7, Crescentino soil

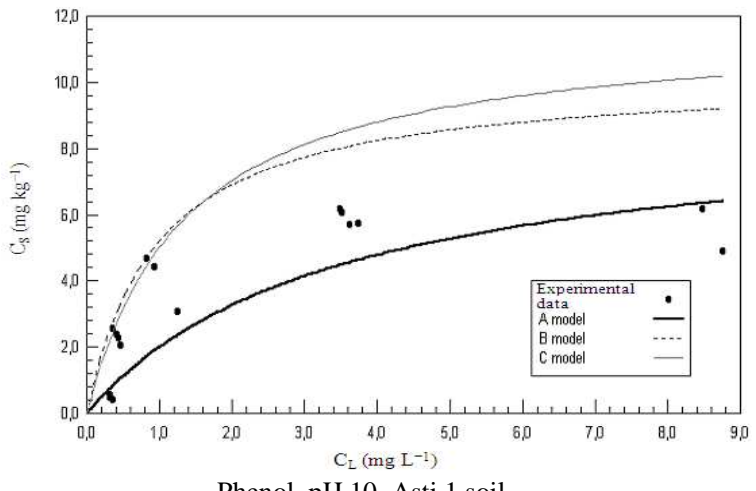

Phenol, pH 10, Asti 1 soil 

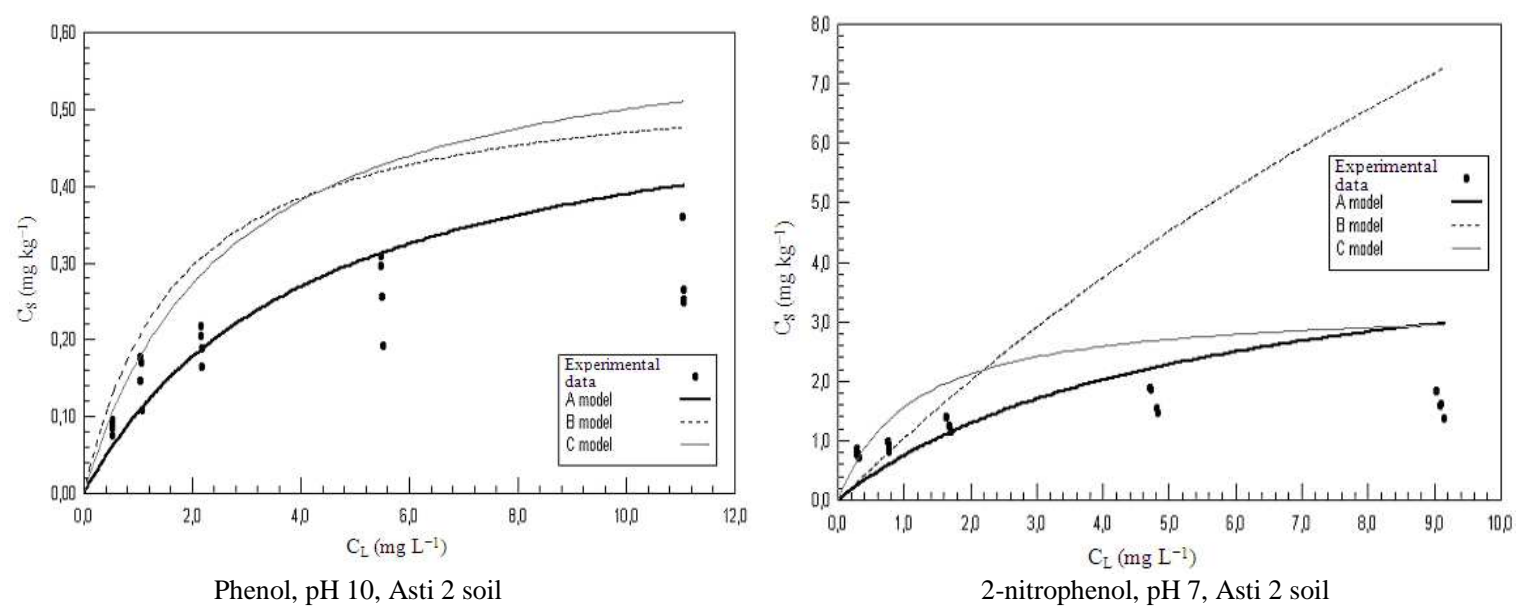

Fig. 3: Sorption of phenol and 2-nitrophenol on Crescentino, Asti 1 and Asti 2 soil samples calculated by means of $\mathrm{A}, \mathrm{B}$ and $\mathrm{C}$ DMMs and comparison with the experimental data

Taking into account phenol sorption at $\mathrm{pH} 10$ on the three soil samples, there is generally an agreement between the experimental and calculated isotherms. The A model confirms its reliability considering Crescentino and Asti 1 soil, particularly for phenol at $\mathrm{pH}$ 10, although the $\mathrm{C}$ model appears quite accurate in describing sorption al low concentration values for 2-nitrophenol at $\mathrm{pH} 7$. Considering Asti 2 soil, the organic carbon content is extremely low and adsorption becomes the main interaction mechanism, leading to a very prominent non linearity and to a non reliability of all the applied DMMs.

\section{CONCLUSION}

Actually the most important limit of LFERs is the assumption that the sorption is due exclusively to the partitioning of the un-dissociated pollutant in soil organic fraction, thus ignoring adsorption and they aren't able to explain the nonlinearity of sorption phenomena. Moreover each LFER is derived from a definite set of experimental data, referred to a certain type of soil and analytical conditions.

Furthermore the calculation of the coefficients $K_{D}$, theoretical(1) and $\mathrm{K}_{\mathrm{D}}$, theoretical(2) presumes a neglectable difference between the values referred to $\mathrm{pH} 4$ and the ones referred to $\mathrm{pH} \mathrm{7,} \mathrm{because} \mathrm{both} \mathrm{LFERs} \mathrm{(Eq.} 1$ and 2) don't consider the adsorption of the un-dissociated phenols and the $\mathrm{pH}$ dependence of these processes.

The fact that the $\mathrm{K}_{\mathrm{D}}$ experimental values are higher at $\mathrm{pH} 4$ than at $\mathrm{pH} \mathrm{7,} \mathrm{allows} \mathrm{the} \mathrm{researchers} \mathrm{to}$ hypothesize that the main sorption mechanism is certainly the partitioning of the neutral pollutant in $\mathrm{SOM}$, but that the interactions that happen at $\mathrm{pH} 4$ on soil mineral surface (mainly not specific interactions) are higher than the ones happening at $\mathrm{pH}$ 7. These hypotheses may be confirmed by the fact that the only cases in which the experimental $\mathrm{K}_{\mathrm{D}}$ values are close to the theoretical ones concern $\mathrm{K}_{\mathrm{D} \text {, theoretical(1) }}$ calculated for phenol at $\mathrm{pH} 7$ on Crescentino and Asti 1 soils.

DMMs calculate the sorption of a certain HIOC as the sum of the neutral and ionic species contributes, considering an ideal coexistence of the processes. The difference among the three DMMs is that "A" model hypothesizes the partitioning of the neutral pollutant in soil organic matter, supposed homogenous, thus implying a linear isotherm, while " $\mathrm{B}$ " and " $\mathrm{C}$ " models suppose interactions involving the heterogeneous soil organic fraction and mineral surface, thus implying nonlinearity for all the pollutant species.

The interactions between the considered pollutants and soil samples regard heterogeneous matrixes and are probably mainly specific, the active sites reach saturation easily and a competition may happen between the neutral and phenolate species for the active sites on soil organic fraction and mineral surface, thus leading to a total sorption below the calculated value considering separately the two contributes of the neutral and ionic pollutants. The agreement between the calculated and the experimental isotherms increases for higher pollutant concentration values in the aqueous phase and for higher soil organic carbon content.

\section{REFERENCES}

1. Luthy, R.G., G.R. Aiken, M.L. Brusseau, S.D. Cunningham and J.C. Westall, 1997. Sequestration of hydrophobic organic contaminants by geosorbents. Environ. Sci. Technol., 31: 3341-3347. http://cat.inist.fr/?aModele=afficheN\&cpsidt=2098175 
2. Chiou, C.T. and D.E. Kile, 1998. Deviations from sorption linearity on soils of polar and nonpolar organic compounds at low relative concentrations. Environ. Sci. Technol., 32: 338-343. http://cat.inist.fr $/$ aModele $=$ afficheN $\&$ cpsidt $=2158291$

3. Stone, A.T., 1987. Reductive dissolution of manganese (III/IV) oxides by substituted phenols. Environ. Sci. Technol., 21: 979-988. http://pubs.acs.org/doi/abs/10.1021/es50001a011

4. Ulrich, H.J. and A.T. Stone, 1989. Oxidation of chlorophenols adsorbed to manganese oxide surfaces. Environ. Sci. Technol., 23: 421-428. http://pubs.acs.org/doi/abs/10.1021/es00181a006

5. Jafvert, C.T., J.C. Westall, E. Grieder and R.P. Schwarzenbach, 1990. Distribution of hydrophobic ionogenic organic compounds between water and octanol. Environ. Sci. Technol., 24: 1795-1803. http://pubs.acs.org/doi/abs/10.1021/es00082a002

6. Westall, J.C., C. Leuenberger and R.P. Schwarzenbach, 1985. Influence of $\mathrm{pH}$ and ionic strenght on the aqueous.-nonaqueous distribution of chlorinated phenols. Environ. Sci. Technol., 19: 193-198. http://cat.inist.fr/?aModele $=$ afficheN\&cpsidt $=9050$ 419

7. Schellenberg, K., C. Leuenberger and R.P. Schwarzenbach, 1984. Sorption of chlorinated phenols by natural sediments and aquifer materials. Environ. Sci. Technol., 18: 652-657. http://cat.inist.fr/?aModele $=$ afficheN\&cpsidt $=8990$ 275

8. Lee, L.S., P.S. Rao and M.L. Brusseau, 1991. Nonequilibrium sorption and transport of neutral and ionised chlorophenols. Environ. Sci. Technol., 25: 722-729.

http://cat.inist.fr/?aModele $=$ afficheN\&cpsidt $=1139$ 8923

9. Boyd, S.A., 1982. Adsorption of substituted phenols by soil. Soil Sci., 134: 337-343. http://journals.lww.com/soilsci/pages/articleviewer. aspx ?year $=1982 \&$ issue $=11000 \&$ article $=00007 \&$ ty pe $=$ abstract

10. U.S. EPA, 1999. Screening level ecological risk assessment protocol for hazardous waste combustion facilities.

http://www.atmpro.be/pdf/Chpt1-ecorisk.pdf
11. Stapleton, M.G., D.L. Sparks and S.K. Dentel, 1994. Sorption of pentachlorophenol to HDTMAclay as a function of ionic strength and $\mathrm{pH}$. Environ. Sci. Technol., 28: 2330-2335. http://cat.inist.fr/?aModele $=$ afficheN\&cpsidt $=3347$ 843

12. Bartels, J.M., 1996. Methods of Soil Analysis Part 3. Chemical Methods. American Society of Agronomy-Soil Science Society of America, Madison, Wiscounsin, ISBN: 10: 0891188258, pp: 1264.

13. Fiore, S., M.C. Zanetti and G. Genon, 2003. Experimental study of the $\mathrm{pH}$ influence on the transport mechanisms of phenols in soil. Ann. Chim. $\quad$ Rome, 53: 595-605. http://www.ncbi.nlm.nih.gov/pubmed/12911152

14. Graber, E.R. and M.D. Borisover, 1998. Evaluation of the glassy/rubbery model for soil organic matter. Environ. Sci. Technol., 32: 3286-3292. http://pubs.acs.org/cgibin/jtext?esthag/32/i21/abs/es9801238

15. Xia, G. and J.J. Pignatello, 2001. Detailed sorption isotherms of polar and apolar compounds in a highorganic soil. Environ. Sci. Technol., 35: 84-94. http://cat.inist.fr/?aModele=afficheN\&cpsidt $=851511$

16. Schwarzenbach, R.P. and D.M. Gschwend, 1993. Environmental Organic Chemistry. John Wiley and Sons, Chichester, pp. 681.

17. Haderlein, S.B. and R.P. Schwarzenbach, 1993. Adsorption of substituted nitrobenzenes and nitrophenols to mineral surfaces. Environ. Sci. Technol., 27: 316-326. http://cat.inist.fr/?aModele $=$ afficheN\&cpsidt $=4559457$

18. Schwarzenbach, R.P., R. Stierli, B.R. Folsom and J. Zeyer, 1988. Compound properties relevant for assessing the environmental partitioning of nitrophenols. Environ. Sci. Technol., 22: 83-92. http://pubs.acs.org/doi/abs/10.1021/es00166a009

19. Weissmahr, K.W., S.B. Haderlein and R.P. Schwarzenbach, 1997. In situ spectroscopic investigations of adsorption mechanisms of nitroaromatic compounds at clay minerals. Environ. Sci. Technol., 31: 240-247. http://cat.inist.fr/?aModele $=$ afficheN\&cpsidt $=2550$ 658 